\title{
Engaging communities in supporting HIV prevention and adherence to antiretroviral therapy in Zambia
}

Fiona Samuels

Joseph Simbaya

Avina Sarna

Population Council

Scott Geibel

Population Council

Phillimon Ndubani

See next page for additional authors

Follow this and additional works at: https://knowledgecommons.popcouncil.org/departments_sbsr-hiv

Part of the Demography, Population, and Ecology Commons, Family, Life Course, and Society Commons, Gender and Sexuality Commons, International Public Health Commons, and the Medicine and Health Commons How does access to this work benefit you? Let us know!

\section{Recommended Citation}

Samuels, Fiona, Joseph Simbaya, Avina Sarna, Scott Geibel, Phillimon Ndubani, and Jolly Kamwanga. 2008. "Engaging communities in supporting HIV prevention and adherence to antiretroviral therapy in Zambia," Horizons Research Summary. Washington, DC: Population Council. 


\section{Authors}

Fiona Samuels, Joseph Simbaya, Avina Sarna, Scott Geibel, Phillimon Ndubani, and Jolly Kamwanga 


\section{Engaging Communities in Supporting HIV PreVention and AdHerence to ANTIRETROVIRAL THERAPY IN ZAMBIA}

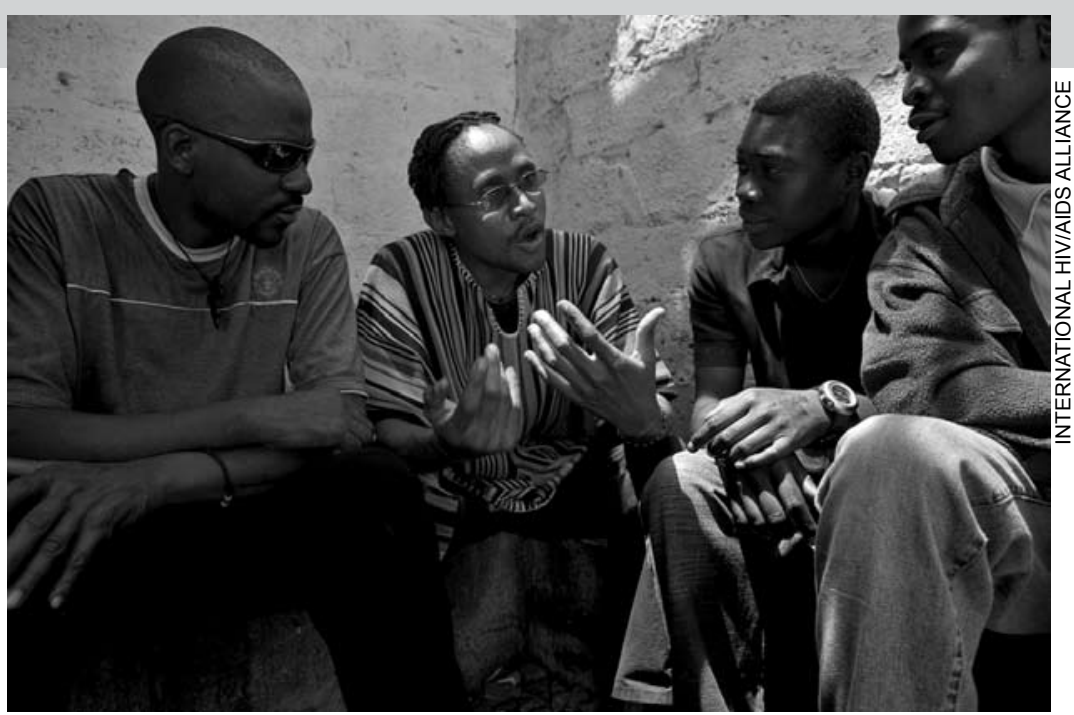

Treatment support worker talks to community members in Lusaka

Recognizing the urgent need for antiretroviral therapy (ART), the Government of the Republic of Zambia (GOZ) has taken important steps to increase access to ART around the country, including making ART and associated laboratory tests free of charge at public health facilities (GOZ 2005). As a result, the number of people receiving ART has increased from 8,500 in June 2004 to a total of 115,000 by July 2007.

Because of the increased demands resulting from the scaling up of ART, it is clear that the formal health system alone cannot carry out all the steps necessary to get large numbers of people to initiate and maintain treatment successfully, and to prevent further transmission of HIV. Therefore, innovative approaches are necessary to ensure effective coordi-

nation between hospitals, clinics, and communitybased education and support services.

This summary presents findings from an operations research study to assess the outcomes of the Antiretroviral Community Education and Referral (ACER) Project in two urban areas in Zambia-Lusaka and Ndola. The ACER project was implemented by the International HIV/AIDS Alliance, based in England, and the Alliance's Zambia office, in conjunction with local Zambian partners. Launched in mid-2004, the two-year project built on previous formative research with urban and rural communities that examined knowledge and attitudes about prevention and treatment (International HIV/AIDS Alliance 2003). 
ACER was the Alliance's first attempt to put into practice a community engagement strategy to foster HIV prevention, treatment, care, and support for people living with and affected by HIV/AIDS. Community engagement involves bringing together people with HIV, community stakeholders, and health providers to develop partnerships, address service gaps and difficulties, and support families and individuals, with the following aims:

- Increase community awareness of available HIVrelated services.

- Increase access to and use of those services through referral systems.

- Increase community understanding of the connections between HIV prevention, care, and treatment.

- Support individuals to successfully adhere to treatment and practice preventive behaviors.

- Support health care workers to deliver services and to help meet their own health needs.

The research was conducted by the Institute of Economic and Social Research (INESOR) in Zambia and the Horizons Program. This summary addresses the following key research questions of the study:

- Among people on ART and community members, what are their levels of knowledge about HIV and ART, uptake of HIV testing, serostatus disclosure, adherence to ART, sexual risk-reduction behavior, and stigma, and how have these levels changed over time?

- What has been the effect of the ACER Project on the above outcomes among individuals on ART and community members?

\section{Intervention Partners and Activities}

In order to implement ACER, the Alliance worked with several partners in Zambia. These were the Network for Zambian People Living with HIV and AIDS (NZP+); Traditional Health Practitioners Association of Zambia (THPAZ); home-based care (HBC) programs affiliated with the Archdiocese of Lusaka and the Catholic diocese of Ndola; Africa Directions in Lusaka (a youth-led NGO); the Central Board of Health; and public clinics offering ART in Lusaka and Ndola.
The Alliance hired a full-time coordinator to run the project in the intervention sites, liaise with the partners, and provide technical support and guidance. Additionally, in each of the two intervention communities, the Alliance hired two full-time treatment support workers (TSWs) who were based in the ART clinics and one fulltime treatment mobilizer (TM). The TMs coordinated partner activities in the intervention sites and acted as the link between community partners and the TSWs in the ART clinics.

There were five main types of ACER activities, all of which were inter-related and built on each other.

\section{Capacity building for partners}

The capacity building program was conducted by the Alliance's Zambia office as well as the Alliance Secretariat, with support from international consultants. The training aimed to ensure that partners got to know each other and were familiar with the basics of HIV, prevention, and ART. In 2006, for instance, the project trained 164 people from the different partner organizations (106 women and 58 men). Topics covered included information about antiretrovirals (ARVs), including how they work, what types are available in Zambia, their side effects, and guidance on how to support adherence among people on ART.

\section{Community activities}

Once the partners were trained, they carried out four broad types of activities in the intervention sites in Lusaka and Ndola. These were: conducting sensitization and educational activities, setting up support groups for people on ART, providing home-based care, and making referrals to health and community services. Each partner carried out activities based on their areas of expertise and comparative advantage; overlapping and complementarity of activities was widespread. The following illustrates the types of activities that the partners undertook in the communities, and identifies, where available, some figures showing the numbers of people reached, supported, or sensitized. 
$\mathrm{NZP}+$

- Formed support groups for people on ART and their "buddies."

- Educated support group leaders about HIV, ART, and HIV prevention, and provided condoms.

- Referred support group members and leaders to ART and other health services.

- Participated in community radio programs on HIV, ART, stigma, and discrimination.

- As of December 2006, formed 6 support groups of people living with HIV, each with approximately 25 members. Members met regularly and shared information on treatment, and received nutritional support and condoms.

\section{THPAZ:}

- Educated traditional healers and traditional birth attendants about HIV prevention, HIV counseling and testing, ART, and prevention of mother-to-child transmission (PMTCT).

- Referred healers and birth attendants to HIV-related services.

- Used traditional ceremonies to educate and sensitize people about HIV and ART.

- Discussed ways to reduce the risk of HIV transmission during traditional practices such as cutting and circumcision, and distributed gloves and clean razors.

- Distributed condoms and information on HIV prevention and ART at market stalls.

- From January to December 2006, THPAZ in Lusaka reported reaching 3,471 people $(1,899$ women; 1,572 men); in Ndola they reported reaching 10,059 people ( 6,754 women, 3,305 men).

Home-based care programs:

- Referred people for voluntary HIV counseling and testing (VCT), ART, and PMTCT.

- Monitored and supported people on ART and TB treatment and followed up through home visits.

- Trained volunteers and primary caregivers on issues related to ART.

- Provided treatment support for people on ART, including adherence counseling, and food and transport assistance.

- Formed support groups for people on ART.

- Initiated and participated in HIV and ART education activities in the community.
- As of December 2006, the HBC programs had 45 volunteer caregivers supporting 400 people living with HIV, of which 370 (240 female and 130 male) were on ART; prior to ACER, only 20 people living with HIV were on ART.

Africa Directions (Lusaka only):

- Ran a youth drop-in center that provided education on HIV, sexual and reproductive health, and ART.

- Carried out awareness-raising activities on HIV, VCT, ART, and stigma through drama and traditional dance competitions.

- Trained youth peer educators on VCT, ART, stigma and discrimination.

- Promoted and referred youth for VCT.

- Between January and December 2006, reported reaching 1,888 young people (1,103 women and 785 men).

\section{Clinic activities}

At each ART clinic serving the Lusaka and Ndola intervention sites, there was a male and a female TSW openly living with HIV, working alongside the health care workers, and acting as referral contacts for people attending the clinics. Their main activities were to provide adherence counseling, information, referrals to community support organizations, and support for prevention practices and stigma reduction. In 2006, the TSWs provided adherence counseling to 1,944 people (846 males and 1,098 females). The TSWs also coun-

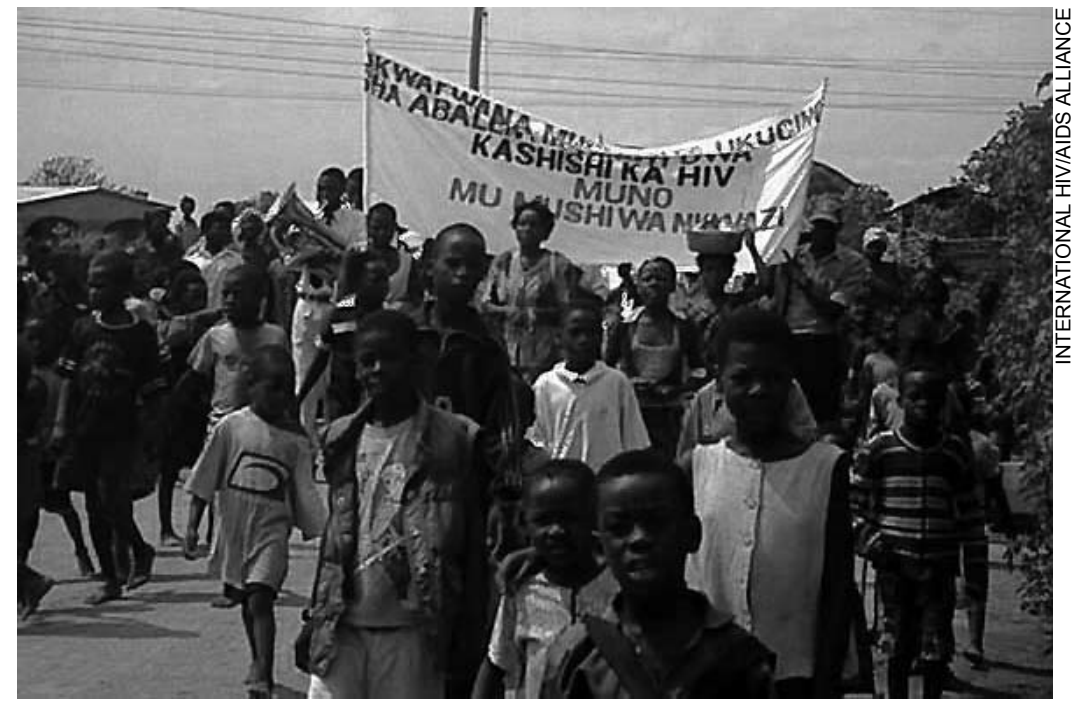

Launch of the ACER project in Ndola 
seled health care workers, provided adherence support to children on treatment, and distributed condoms.

\section{Referrals}

The development of a two-way community referral system was a key feature of the ACER project, and was a means of linking activities in the community and in the clinic (see above). It was a paper-based referral system, using two-part duplicate forms-each entry was numbered to support tracking of clients within the system. A person in need of care was given a referral form by a partner organization working in the community and took it to the place they were referred to-usually the local clinic or the government ART clinic. After clinic staff (often the TSW) had seen the client, they handed the tear-off portion of the form to the client to take back to the organization that made the referral, for ongoing support and follow-up. Depending on circumstances, the TSWs and/or the TM might accompany the person back to the community organization to ensure that they were aware of what had happened.

Community and health system partners held regular referral coordination meetings to track the performance of the system and to discuss issues and needs for individual clients. This was to ensure that the system ran smoothly and that all partners felt ownership of the system, which they helped to develop through a participatory process.

\section{Development of materials}

A final important aspect of the project was the development of educational materials on issues that ACER addressed. These materials were used during the implementation of ACER and now are more widely used for other projects. Materials included a set of fact sheets on HIV and ART, leaflets, and a manual entitled, Community Engagement for Antiretroviral Treatment.

\section{Methodology}

The study used a quasi-experimental, comparative preand post-test design to measure the effects of the intervention. The study was carried out in two cities, Lusaka and Ndola, because of high levels of HIV among resi- dents there and because the government initiated the pilot phase of its ART program in 2004 in these cities. Study sites included one intervention and one comparison site in Lusaka (Ng'ombe and Bauleni, respectively) and in Ndola (Nkwazi and Kaloko, respectively). The study sites were high-density, low income communities that were easy to delineate from the surrounding areas, and were similar in terms of size, infrastructure, and other HIV program/projects operating in the site at the time the study was initiated.

Cross-sectional qualitative and quantitative data were collected at two points in time: baseline data between November 2004 and March 2005 and endline data collected post-intervention, between July and December 2006. Quantitative data were collected via a community survey and a survey of people on ART. The qualitative data were collected via in-depth interviews and focus groups with people on ART and their treatment supporters, and intervention partners and their clients. The quantitative data were analyzed using SPSS; the qualitative data were translated, transcribed, and analyzed using Atlas.ti $i^{\odot}$.

The study received ethical approval from the University of Zambia and the Population Council.

\section{Description of samples}

\section{Survey of people on ART}

In Lusaka, people on ART were recruited at the University of Zambia (UNZA) clinic, a large public sector clinic, which serves residents from Ng'ombe, the intervention site. They were also recruited from Bauleni clinic, a similarly large, public sector facility in Bauleni, the comparison site. In Ndola, people on ART from Nkwazi, the intervention site, were recruited from the ART clinic at the government-run Ndola Central Hospital. Due to the non-availability at baseline of persons on ART from Kaloko, no interviews were undertaken with individuals from the Ndola comparison site at baseline or endline. All consenting individuals over 18 years of age were recruited sequentially as they came in for ART and care services at the selected health facilities.

As shown in Table 1, in all sites and both at baseline and endline, more woman were interviewed than men 
(60-70 percent). The mean age (around 40) was similar across sites and for baseline and endline. About half of those interviewed were married, and significant proportions were separated, divorced, or widowed (39-53 percent). In most study sites, the majority had completed primary school.

\section{Community survey}

The households in the study sites were mapped to develop a sampling frame for a community survey, and stratified random sampling was employed to select respondents between 18 and 55 years of age. The sample was stratified by age (18-30 years, $31-55$ years) and sex. The sample size was calculated to detect a significant difference in uptake of VCT in intervention sites after the duration of the intervention. The final sample size was approximately 300 in each community at baseline and endline.

In the community survey, about half the sample were women at baseline and endline, except for Nkwazi, where the endline sample was more than two-thirds women (67 percent). In comparison to the survey with people on ART, the mean age of both men and women in the community survey at both baseline and endline was younger, i.e., for women it was around 30 and for men around 31, and this was true for both the intervention and comparison sites (see Table 2). In terms of monthly household income and ownership of assets, people on ART were poorer than the general community; this was particularly the case in Ndola where the majority of respondents were found in the lowest economic status category based on asset ownership.

\section{In-depth interviews and focus groups}

People on ART were recruited for in-depth interviews (IDIs) through HBC programs in the three study sites where ART programs were operating: Ng'ombe and Bauleni (Lusaka), and Nkwazi (Ndola). At baseline a total of 12 people on ART per site were interviewed; at endline this was reduced to 8 since the team felt that a saturation point had been reached such that the same information was being provided by respondents.

The age range of the 15 women and 9 men who participated in IDIs at endline was 17 to 56 years (mean age for women 41 ; mean for men 45). The majority of

Table 1 Sociodemographic characteristics of respondents on ART

\begin{tabular}{|c|c|c|c|c|c|c|}
\hline & \multicolumn{4}{|c|}{ Lusaka } & \multirow{2}{*}{\multicolumn{2}{|c|}{$\begin{array}{c}\text { Ndola } \\
\text { Nkwazi }\end{array}$}} \\
\hline & \multicolumn{2}{|c|}{ Ng'ombe } & \multicolumn{2}{|c|}{ Bauleni } & & \\
\hline & $\begin{array}{l}\text { Baseline } \\
(n=120)\end{array}$ & $\begin{array}{c}\text { Endline } \\
(n=188)\end{array}$ & $\begin{array}{l}\text { Baseline } \\
(n=125)\end{array}$ & $\begin{array}{c}\text { Endline } \\
(\mathrm{n}=187)\end{array}$ & $\begin{array}{c}\text { Baseline } \\
(\mathrm{n}=77)\end{array}$ & $\begin{array}{c}\text { Endline } \\
(\mathrm{n}=126)\end{array}$ \\
\hline \multicolumn{7}{|l|}{ Sex } \\
\hline Male (\%) & 33 & 30 & 32 & 35 & 39 & 40 \\
\hline Female (\%) & 67 & 70 & 68 & 65 & 61 & 60 \\
\hline \multicolumn{7}{|l|}{ Age } \\
\hline Male (mean) & 40 & 40 & 40 & 41 & 38 & 40 \\
\hline Female (mean) & 36 & 36 & 36 & 37 & 37 & 37 \\
\hline \multicolumn{7}{|l|}{ Marital status } \\
\hline Married (\%) & 40 & 55 & 52 & 52 & 47 & 49 \\
\hline Never married (\%) & 8 & 6 & 6 & 9 & 0 & 2 \\
\hline Separated/Divorced/Widowed (\%) & 53 & 39 & 42 & 39 & 53 & 49 \\
\hline \multicolumn{7}{|l|}{ Highest education level } \\
\hline None (\%) & 8 & 12 & 8 & 11 & 27 & 10 \\
\hline Primary completed (\%) & 52 & 52 & 52 & 47 & 43 & 64 \\
\hline Secondary completed (\%) & 40 & 36 & 40 & 42 & 30 & 27 \\
\hline
\end{tabular}


Table 2 Sociodemographic characteristics of community survey respondents

\begin{tabular}{|c|c|c|c|c|c|c|c|c|}
\hline & \multicolumn{4}{|c|}{ Lusaka } & \multicolumn{4}{|c|}{ Ndola } \\
\hline & \multicolumn{2}{|c|}{ Ng'ombe } & \multicolumn{2}{|c|}{ Bauleni } & \multicolumn{2}{|c|}{ Nkwazi } & \multicolumn{2}{|c|}{ Kaloko } \\
\hline & $\begin{array}{c}\text { Baseline } \\
n=300\end{array}$ & $\begin{array}{l}\text { Endline } \\
n=294\end{array}$ & $\begin{array}{c}\text { Baseline } \\
n=303\end{array}$ & $\begin{array}{l}\text { Endline } \\
\mathrm{n}=297\end{array}$ & $\begin{array}{c}\text { Baseline } \\
n=300\end{array}$ & $\begin{array}{l}\text { Endline } \\
\mathrm{n}=300\end{array}$ & $\begin{array}{c}\text { Baseline } \\
\mathrm{n}=300\end{array}$ & $\begin{array}{l}\text { Endline } \\
\mathrm{n}=300\end{array}$ \\
\hline \multicolumn{9}{|l|}{ Sex } \\
\hline Male (\%) & 47 & 50 & 45 & 39 & 45 & 33 & 45 & 42 \\
\hline Female (\%) & 53 & 50 & 55 & 61 & 55 & 67 & 55 & 58 \\
\hline \multicolumn{9}{|l|}{ Age } \\
\hline Male (mean) & 30 & 32 & 31 & 32 & 32 & 32 & 31 & 34 \\
\hline Female (mean) & 29 & 30 & 29 & 30 & 32 & 31 & 30 & 33 \\
\hline \multicolumn{9}{|l|}{ Marital status } \\
\hline Married (\%) & 65 & 68 & 70 & 66 & 67 & 61 & 76 & 73 \\
\hline Never married (\%) & 28 & 25 & 25 & 23 & 16 & 25 & 14 & 16 \\
\hline $\begin{array}{l}\text { Separated/Divorced/ } \\
\text { Widowed (\%) }\end{array}$ & 8 & 7 & 5 & 10 & 17 & 15 & 11 & 11 \\
\hline \multicolumn{9}{|l|}{ Highest education level } \\
\hline None (\%) & 8 & 4 & 6 & 7 & 8 & 8 & 3 & 8 \\
\hline Primary completed (\%) & 43 & 38 & 41 & 42 & 59 & 60 & 62 & 57 \\
\hline Secondary completed (\%) & 49 & 58 & 54 & 51 & 33 & 32 & 34 & 35 \\
\hline
\end{tabular}

respondents had a primary education. Twelve respondents were married and ten were widowed.

The team also conducted IDIs with individuals who support people on ART to understand their perspectives and experiences (21 supporters at baseline and 20 at endline across the three sites: Ng'ombe, Bauleni, and Nkwazi). A total of 15 clients of traditional healers, members of $\mathrm{NZP}+$, and $\mathrm{HBC}$ workers were interviewed at baseline and 21 at endline from the two intervention sites: Ng'ombe and Nkwazi. Additionally, seven focus groups were held at baseline and eight at endline with intervention partners.

\section{Key Findings}

\section{There was a significant increase among people on ART in Lusaka who cited peer groups as a source of information.}

The study found that over time there was a significant increase, especially in Lusaka, of people on ART reporting that peer groups for people living with HIV were an important source of information. At baseline, only 1 percent of people in Lusaka reported peer groups as a source of information; this rose significantly to 30 percent in $\mathrm{Ng}$ 'ombe and to 47 percent in Bauleni.

Despite this increase, the radio remained the main source of information on HIV/AIDS for all survey participants at all sites. Friends and family were also an important source of information for people on ART in all sites, especially at endline. Overall, more men than women (47 percent vs. 37 percent) received information through the radio while more women (27 percent) received information from health workers than men (10 percent).

The IDIs with people on ART suggested that while $\mathrm{TV}$, radio, and friends were the principal sources, now, especially in the intervention sites, information is often obtained from support groups, the HBC teams, workshops, and from sensitization activities at the clinic. In Bauleni, the clinic was mentioned more often as a source of information about ART than in the intervention sites. However, misinformation and misconceptions also seemed to be more frequent among the Bauleni sample. According to one informant: 
I heard about them [ART] from people who came in our compound to sensitize people but we did not pay much attention to what they were telling us. Because there was another rumor that some Satanists were in the compound asking for blood.

Female, Bauleni

In terms of the kind of information given, all respondents were told about the importance of adhering to ART, how the virus works in the body, and the importance of taking drugs at the same time each day. They were also counseled about CD 4 counts, the importance of taking food with the drugs, and managing side effects. Some respondents reported, though less so in Bauleni, that they received information about sexual and reproductive behavior.

\section{HIV knowledge increased over time but there was little difference between the intervention and comparison sites.}

The community survey showed a small but significant increase in knowledge across all sites from baseline to endline, particularly regarding knowledge about HIV transmission, but the increase was not significantly different between intervention and comparison sites. Overall, respondents in Lusaka had a greater understanding of ART compared with respondents in Ndola.

Despite high levels of knowledge, there were still misconceptions: substantial proportions still believed that HIV can be transmitted through mosquito bites, and some doubted the role condoms play in prevention. Additionally, many respondents did not yet see HIV as a chronic disease, and knowledge about how to manage the side effects of ART were not generally known by people in the community.

\section{HIV testing significantly increased in the Ndola intervention site over the study period.}

Overall, a fourth to more than a third of community survey respondents had undergone HIV testing. In $\mathrm{Ng}$ 'ombe, the Lusaka intervention site, figures were similar at baseline and endline, with approximately 39 percent reported having had an HIV test. In Bauleni the percentage increased from 32 percent at baseline to

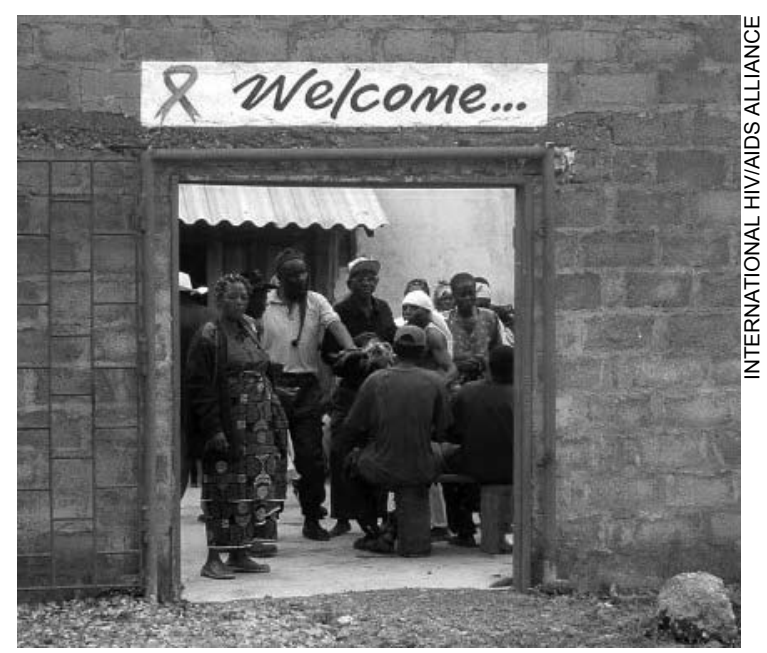

The Network for Zambian People Living with HIV and AIDS drop-in center in Nkwazi.

37 percent at endline. In Ndola 25 percent of respondents at baseline in Nkwazi (the intervention site) reported having had an HIV test, increasing significantly to 35 percent $(\mathrm{p}=0.005)$ at endline; in Kaloko the figures rose slightly from 24 percent at baseline to 29 percent at endline.

The data also showed that women tested significantly more often than men. Of the total number of respondents from the community survey who reported having had an HIV test, 45 percent said they tested because they just wanted to know their status.

\section{Partner disclosure among people on ART remained about the same in the study sites.}

Among people on ART in Lusaka who reported in the survey that they had disclosed to someone, disclosure to partners in $\mathrm{Ng}$ 'ombe went from 41 percent at baseline to 52 percent at endline, and in Bauleni from 47 percent to 56 percent. However, these increases were not statistically significant. In Nkwazi, the Ndola site, it remained the same, i.e., 48 percent of people had disclosed to their spouses at baseline and endline.

The IDIs with people on ART revealed no differences between the intervention and comparison sites regarding HIV testing and disclosure. The main reason for testing was that people were symptomatic.

It was because my husband became ill and died. I also felt ill and I had herpes zoster so I wanted 
to know my illness. I asked the HBC worker to take me for testing.

Female, Nkwazi

Generally people reported no problems accessing testing, and reported positive counseling experiences. There was a sense that fear in disclosing one's status has diminished in all sites. When reviewing patterns of disclosure, spouses tended to disclose to each other first, often going together for testing.

I didn't experience any difficulties [in having a test] because transport was provided by the homebased care. Myself and husband went for it.

Female, Ng'ombe

The availability of ART has played a key role in people being more willing to go for testing since they now know there is something they can do if they test positive.

\section{Mean 4-day self-reported adberence was very high in all sites, but decreased over longer periods of recall.}

At baseline the majority of respondents in both Lusaka and Ndola reported being on ART for less than three months; by endline, the majority had been on treatment for at least six months and nearly half for 12 months or more. The majority of respondents in all sites were receiving first line ART regimens. In Ndola over 90 percent of people both at baseline and endline were receiving Triomune, a fixed dose combination medication in a single pill taken twice daily. In Lusaka, there was more variation. The majority of respondents in all study sites reported ease in taking medications.

Adherence was based on patient self report; a 4-day recall was used as the main measure of adherence. Mean 4-day self-reported adherence was over 99 percent in all sites at both baseline and endline. But when asked about adherence in the past week, significantly fewer respondents reported no missed doses at endline compared to baseline in Ng'ombe. There was no significant change over the study period in Bauleni and Nkwazi (see Table 3).

Overall, self-reported adherence was better in Ndola than in Lusaka; this could be explained by the fact that the drug regimen was simpler there than in Lusaka where regimens other than Triomune were mentioned more frequently.

There was no significant difference in adherence in the past week between male and female respondents. Additionally there was no relationship between marital status or disclosure and adherence measures.

The majority of people in the IDIs had been on ART for less than a year. Knowledge about how and when to take ART was high in all three sites. Most people in

Table 3 Changes in adherence among respondents on ART by site

\begin{tabular}{|c|c|c|c|c|c|c|}
\hline & \multicolumn{4}{|c|}{ Lusaka } & \multirow{2}{*}{\multicolumn{2}{|c|}{$\begin{array}{l}\text { Ndola } \\
\text { Nkwazi }\end{array}$}} \\
\hline & \multicolumn{2}{|c|}{ Ng'ombe } & \multicolumn{2}{|c|}{ Bauleni } & & \\
\hline & $\begin{array}{l}\text { Baseline } \\
(n=120)\end{array}$ & $\begin{array}{l}\text { Endline } \\
(\mathrm{n}=189)\end{array}$ & $\begin{array}{l}\text { Baseline } \\
(\mathrm{n}=125)\end{array}$ & $\begin{array}{l}\text { Endline } \\
(\mathrm{n}=187)\end{array}$ & $\begin{array}{l}\text { Baseline } \\
(n=77)\end{array}$ & $\begin{array}{l}\text { Endline } \\
(\mathrm{n}=125)\end{array}$ \\
\hline Mean adherence: self-report (past 4 days) (\%) & 99.9 & 99.7 & 100.0 & 100.0 & 100.0 & 99.8 \\
\hline Not missed any pills/doses in past 7 days (\%) & 94.2 & $85.2^{*}$ & 95.2 & 90.9 & 98.7 & 97.6 \\
\hline \multicolumn{7}{|l|}{$\begin{array}{l}\text { When was the last time you missed any doses } \\
\text { of your ARV medication? }\end{array}$} \\
\hline Never skip medications & 79 & 69 & 80 & 99 & 99 & 93 \\
\hline Less than 1 month ago & 11 & 4 & 7 & 0 & 0 & 0 \\
\hline More than 1 month ago & 10 & 27 & 7 & 37 & 1 & 7 \\
\hline
\end{tabular}


all sites received the drugs once a month from the clinic but received fewer days supply at the beginning of treatment. All respondents in all three sites said that they were receiving ART free and none had witnessed any shortage of medicines nor any other problems at the clinic.

Four respondents at endline reported ever having missed a dose; the rest (20) reported taking them consistently. Those who missed doses did so early on in their treatment and this was often a result of side effects and lack of food. The fact that there were not many medicines to take facilitated taking the drugs.

If I were taking many pills it would be difficult but I take only one pill in the morning and one in the evening so I do not face problems.

Female, Ng'ombe

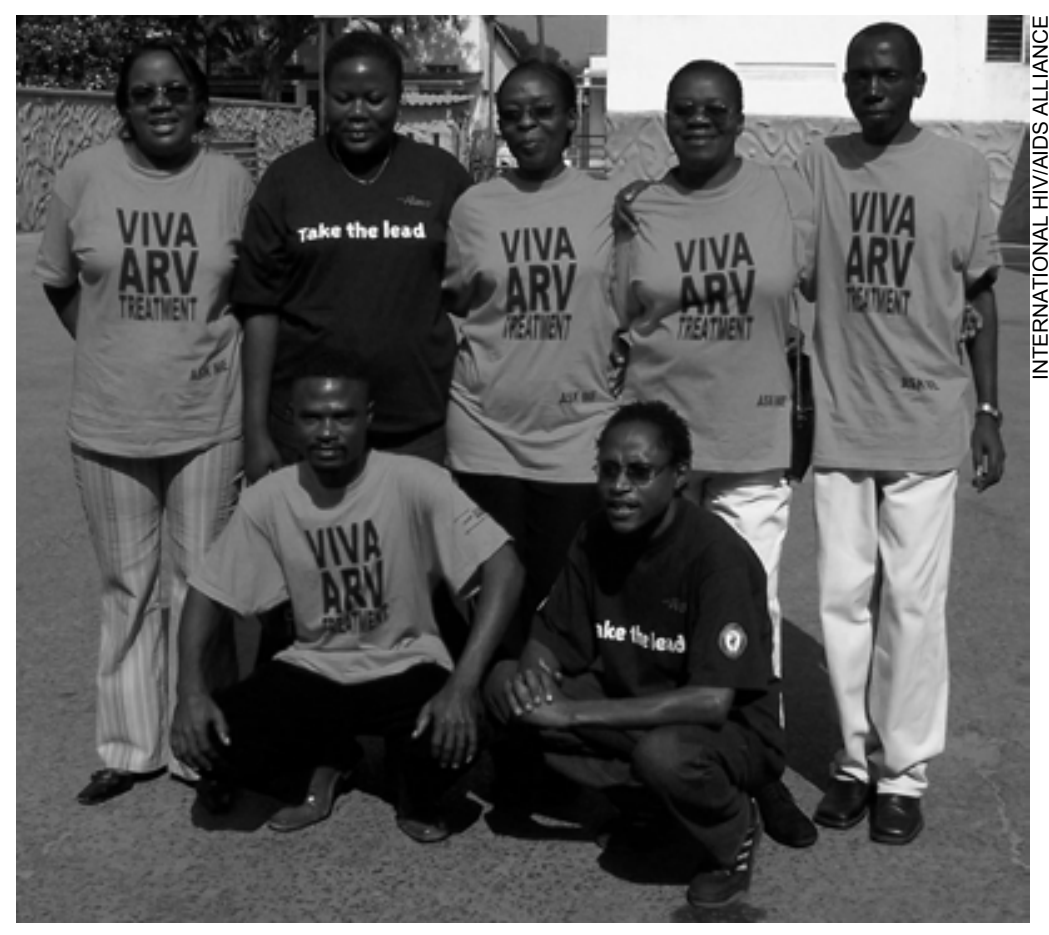

The majority of people had experienced side

ACER team members from Lusaka and Ndola effects, usually early on in their experiences of taking ART; 10 respondents mentioned still having side effects. Most people had been counseled to seek help at the clinic when they experience side effects. Some spoke about changing drugs due to the side effects.

Strategies used to support adherence ranged from using an alarm, clock, or radio; to spouses who are both on ART reminding each other; to children and other family members, including spouses, reminding them; and to $\mathrm{HBC}$ workers reminding them. Generally there was a sense that it is one's duty to remember.

In the past, I was being encouraged by other persons, but nowadays I have learnt to take the pill at the right time on my own.

Female, Nkwazi

\section{There were positive changes in knowledge of partner's status among people on ART in the Lusaka intervention site.}

In the survey with people on ART, around half of the respondents were sexually active; self-reported sexual activity increased significantly over the period of the study among participants at all sites, especially in the intervention sites. The vast majority of sexually active

respondents at all three sites reported sex with regular partners; there was no change over time. Knowledge of partner's HIV status, which implies that the partner had been tested, increased significantly over time in Ng'ombe (62 percent vs. 79 percent; $\mathrm{p}=0.022$ ) compared to Bauleni (59 percent vs 68 percent; $\mathrm{p}=0.205$ ). Condom use at last sex and consistent condom use with regular partners increased in both $\mathrm{Ng}$ 'ombe and Bauleni, but there was no difference between groups at endline.

A small proportion of respondents in all three sites reported sex with non-regular partners. The proportion of respondents reporting non-regular partners in Ng'ombe declined significantly over the study period, while there was a small but not significant increase in the proportion reporting casual partners in Bauleni.

From the IDIs, especially in the intervention sites, there was a sense that people were well informed about the relationship between ART and sex and the importance of using condoms. Most had been taught about safe sex, they knew about re-infection with different strains, and many reported using condoms with their spouses.
Mod: Is there any change in the way you have sex with your husband as compared to before you started taking $A R V$ s? 
Inf: Yes, there is a change because this time we use condoms.

Female, Ng'ombe

In Bauleni, the data suggest that there was less information and teaching being given on ART and sexual relations. Among the informants interviewed, there was a sense that people should not have sex anymore or that they are too old. In response to whether she was taught about sex and HIV prevention, one woman said:

\section{No, in fact I have remained single from the time my husband died and I did not even bother to ask about it.}

Female, Bauleni

Similarly, in the intervention sites there was a sense that more teaching had been provided regarding reproductive health options and possibilities compared to Bauleni. Most people in Ng'ombe and Nkwazi knew about PMTCT and many people mentioned Nevirapine. But there was some distrust of Nevirapine- that if people had children while on it, the children would have health problems.

\section{There were significant reductions in internal- ized stigma among people on ART in Lusaka.}

The research team used a 24-item adaptation of the HIV stigma scale (Berger, Ferrans, and Lashley 2001) to measure internalized stigma (Cronbach's alpha 0.87: possible range of scores 24-96). As shown in Table 4, mean stigma scores significantly decreased in
Ng'ombe and Bauleni. The reduction in stigma scores was observed across all four domains contributing to internalized stigma in Lusaka, but more so across public attitude-related stigma and negative self image. In addition, there was a significant increase in both Lusaka sites of respondents who were categorized as having minimal to low levels of stigma based on their stigma scores. There was no change in stigma measures in Nkwazi, the Ndola site.

The study also found gender differences in internalized stigma. At baseline, women from all sites reported significantly more internalized stigma than men based on mean scores ( 69 vs. $65 ; \mathrm{p}=0.003$ ). At endline, the figures were similar (63 vs. 62 ; NS). This suggests that women on ART across the three sites experienced a greater decline in internalized stigma than men.

\section{Community stigma decreased over the study period in both the intervention and compari- son sites; however, it remained a problem.}

The community survey included 11 questions to assess the level of stigma among study respondents. Overall, levels of stigmatizing attitudes decreased among respondents both in the intervention and comparison sites. For example, at baseline in $\mathrm{Ng}$ 'ombe, 74 percent of people agreed that an HIV-infected person can share his/her food with HIV-negative people, rising to 91 percent at endline $(\mathrm{p}<0.001)$. Similarly, at baseline in Nkwazi, 52 percent of people agreed that HIV/AIDS happens to immoral or promiscuous people; at endline this decreased to 34 percent $(\mathrm{p}<0.001)$.

\section{Table 4 Changes in internalized stigma among people on ART by site}

\begin{tabular}{|c|c|c|c|c|c|c|}
\hline & \multicolumn{4}{|c|}{ Lusaka } & \multirow{2}{*}{\multicolumn{2}{|c|}{$\begin{array}{c}\text { Ndola } \\
\text { Nkwazi }\end{array}$}} \\
\hline & \multicolumn{2}{|c|}{ Ng'ombe } & \multicolumn{2}{|c|}{ Bauleni } & & \\
\hline & $\begin{array}{l}\text { Baseline } \\
(n=120)\end{array}$ & $\begin{array}{l}\text { Endline } \\
(n=189)\end{array}$ & $\begin{array}{l}\text { Baseline } \\
(n=125)\end{array}$ & $\begin{array}{l}\text { Endline } \\
(\mathrm{n}=187)\end{array}$ & $\begin{array}{c}\text { Baseline } \\
(\mathrm{n}=77)\end{array}$ & $\begin{array}{c}\text { Endline } \\
(\mathrm{n}=125)\end{array}$ \\
\hline Total stigma score (mean) & 71 & $64^{*}$ & 65 & $58^{*}$ & 67 & 66 \\
\hline \multicolumn{7}{|l|}{ Total score (categorized) } \\
\hline Minimal to low (\%) & 27 & $40^{* *}$ & 41 & $59^{* *}$ & 19 & 20 \\
\hline Moderate to high (\%) & 73 & 60 & 69 & 41 & 81 & 80 \\
\hline
\end{tabular}

${ }^{*} p<0.001 ;{ }^{* *} p<0.05$ 
In the IDIs with people on ART, in all three sites there was a sense that levels of stigma have gone down in the family, in the general community, among health care workers, and in the workplace. Various reasons were given by respondents, but, importantly, it was often linked to increased knowledge, information, and education about HIV. Respondents also reported that stigma is declining since people are becoming aware that being infected is not necessarily the fault of those infected and that it can happen to anyone. Similarly, it is also going down because almost everyone is somehow affected.

But many respondents in all sites also said that stigma was still present, pointing out that it is often those who are less educated or ignorant who still stigmatize. Some mentioned still distrusting health workers, and others pointed to the need for further training and sensitization of health workers.

A reduction in stigma had also occurred, according to all respondents, because of the availability of ART. People were looking well again, and their self-esteem and confidence had increased; some even said that because they started ART early they never looked sick so they were never stigmatized.

A difference noted between the comparison and intervention sites was that in Bauleni, respondents generally spoke less about information, education, and workshops as having had an influence on stigma. Instead they credited sensitization at the clinic with contributing to stigma reduction rather than activities in the community. Additionally, respondents from Bauleni indicated that there was more hiding of one's serostatus and less disclosure than in the intervention sites. These respondents noted that there was still guilt and shame about being HIV positive and a reluctance to be part of support groups.

\section{Most referrals by community partners were for VCT followed by $A R T$.}

Over the course of the intervention, a total of 1,852 duplicate referral slips were reviewed from the community partners in the intervention sites. In 2005, 58 percent of people were referred for VCT and 29 percent for ART; in 2006, the proportion of VCT referrals increased to 72 percent and those for ART decreased to
18 percent. Overall, in both sites slightly more women than men had been referred and the majority of people were in the $26-35$ age category.

Qualitative data collected from partner organizations and their clients highlight the value of the referral system and their support of it.

... when we are referred we are well received by the doctors at the hospital, we are attended to nicely and given medicine that makes our lives better, so referral projects are benefiting us. Female client of NZP+, Nkwazi

I am urging my colleagues [traditional healers] not to keep the HIV-positive people for a long time. When you see that a person is not improving despite trying different drugs, you should refer him to the hospital so that he can be tested because the most common illness is HIV.

FGD with THPAZ members, Ng'ombe

\section{Conclusions}

The study documents many positive trends among people on ART and community members in the research sites. These include increased knowledge about HIV prevention and ART, greater uptake of HIV testing, increased use of peer networks as an information source, and reduced stigma.

Despite these improvements, there were few statistically significant differences between the intervention and comparison sites. There may be several reasons for this. First, roll-out of the government's ART program and implementation of support activities in the study sites did not happen as anticipated. The intervention site in Lusaka (Ng'ombe) only received an ART clinic in early 2007, meaning that people from this area had to travel to two or three other ART sites outside the intervention area throughout the period of the study, thus making it difficult to maintain close ties between the one study clinic (UNZA) and the community.

In addition, in the Lusaka comparison site, other groups began implementing HIV and ART education and support activities, although these were primarily clinic-based, as opposed to the ACER interventions which were both based in the community and the clinic. Because of these developments, the strength of 
quantitative comparisons between the Lusaka sites was diluted. And in Ndola, the study lost a comparison site due to the inability to recruit sufficient people on ART at baseline.

Although technical support and funds were provided at a high level during the first year of ACER, during the second year and subsequently, funding constraints meant that some community activities and the ongoing skills building program were interrupted. This meant that ACER's efforts did not serve to saturate the sites as had originally been envisaged.

Nonetheless, the study's positive quantitative trends and positive qualitative data suggest that a community engagement approach, which was introduced in both sites with varying areas of emphasis, has had a beneficial effect on the lives of some respondents. Additionally, the ACER interventions introduced new approaches to community engagement, new roles different community groups can play in addressing HIV, and new ways to link clinic and community activities. An important aspect of this was the referral system, which linked the community to the clinic through organizations based in the community. The fact that there was a point person in the clinic, in this case the TSW who acted as the interface between the community and the clinic and who was a person openly living with HIV, was a key aspect of this referral system.

Based on these initial findings and experiences, a scaled-up version of this community engagement approach commenced in Uganda in February 2007 and is already extended across seven districts, with 83 openly-positive network support agents, who combine the functions of the ACER TSWs and TMs to work three days a week in ART clinics and the rest of the time in the community. Within Zambia plans are also developing for a similar extension of the approach to other urban and rural settings in $2008 . \mathcal{R}$

January 2008

\section{References}

Berger, Barbara E., Carol E. Ferrans, and Felissa R. Lashley. 2001. "Measuring stigma in people with HIV: Psychometric assessment of the HIV stigma scale," Research in Nursing and Health 24: 518-529.

Government of the Republic of Zambia [GOZ]. 2005. Free Antiretroviral Therapy (ART): Operational Guidelines for Health Facilities in Zambia, Lusaka. Lusaka: Government of the Republic of Zambia.

International HIV/AIDS Alliance. 2003. "Voices from rural communities: Report of a community consultation on antiretroviral treatment in four villages of Southern Province, Zambia." Brighton, UK: International HIV/AIDS Alliance.

WHO. 2006. "Scaling up HIV/AIDS prevention, treatment and care: a report on WHO support to countries in implementing the 3 by 5 Initiative, 2004-2005." Geneva: WHO.

The research team would like to thank staff from the International HIVIAIDS Alliance, both in Zambia and in the UK, who supported this study throughout. The study would not have been possible without the backing of the Zambian Ministry of Health, both at national and provincial levels. All the intervention partners were vital for providing both logistical and analytical support and guidance. Finally we would like to thank the communities, both in Lusaka and Ndola, who answered our endless questions with good humor and patience.

Study investigators include: Fiona Samuels, Overseas Development Institute/International HIVIAIDS Alliance; Joseph Simbaya, Phillimon Ndubani, and Jolly Kamwanga, Institute of Economic and Social Research, University of Zambia; and Avina Sarna and Scott Geibel, Horizons/Population Council.

Suggested citation: Samuels, Fiona, Joseph Simbaya, Avina Sarna, Scott Geibel, Phillimon Ndubani, and Jolly Kamwanga. 2008. "Engaging communities in supporting HIV prevention and adherence to antiretroviral therapy in Zambia," Horizons Research Summary. Washington, DC: Population Council.

\section{Hprizons $\lambda$}

Population Council/Horizons Communications Unit 4301 Connecticut Avenue, NW Suite 280 Washington, DC 20008

\section{QP Population Council}

Tel: 202-237-9400

Fax: 202-237-8410

horizons@popcouncil.org

www.popcouncil.org/horizons
This research summary is made possible by the generous support of the American people through the United States Agency for International Development (USAID) and the President's Emergency Plan for AIDS Relief under the terms of HRN-A-00-97-00012-00. The contents are the responsibility of the Horizons Program and do not necessarily reflect the views of USAID or the United States Government. 